\title{
Distinguishing between accounts of the A/A'-distinction: the view from Argentinian Spanish Clitic Doubling
}

\author{
Suzana Fong \\ MIT, Department of Linguistics and Philosophy \\ sznfong@mit.edu
}

Received: 15-03-21

Accepted: 30-09-21

Published: 22-02-2022

How to cite: Susana Fong. 2022. Distinguishing between accounts of the A/A'distinction: the view from Argentinian Spanish Clitic Doubling. RLLT17, eds. Ora Matushansky, Laurent Roussarie, Michela Russo, Elena Soare \& Sophie Wauquier. Special issue of Isogloss Open Journal of Romance Linguistics 8(2)/4, 1-17.

DOI: https://doi.org/10.5565/rev/isogloss. 132

\section{Abstract}

The A/A'-distinction underpins case, agreement, and binding properties of moving DPs. It also determines possible movement paths (cf. the Ban on Improper Movement). Van Urk (2015) and Safir (2019) take this distinction not to be a primitive of the grammar; rather, these authors seek to derive the $\mathrm{A} / \mathrm{A}^{\prime}$-distinction from independent principles of the grammar. In both approaches, syntactic positions are not inherently A or A'. Rather, independent and more general properties of the grammar determine, as a byproduct, the nature of the movement that passes through these positions. While these approaches differ in which grammatical components they derive the A/A'-distinction from, both are able to explain the properties that it is based on (e.g. weak crossover, reconstruction, etc). Another similarity is that both approaches allow for a flexible definition of syntactic positions. I will argue that, despite these similarities, we can empirically adjudicate 
between these two theories. Specifically, Di Tullio et al.'s (2019) analysis of clitic doubling in Argentinian Spanish will be shown to be compatible only with Van Urk (2015).

Keywords: clitic doubling, Argentinian Spanish, A/A'-distinction, Insulation, featural definition of syntactic positions

\section{Introduction}

The A/A'-distinction underpins case, agreement, and binding properties of moving DPs. It also determines possible movement paths (cf. the Ban on Improper Movement). The properties that underlie this distinction are summarized below:

Table 1. The A/A'-distinction

\begin{tabular}{|c|c|c|}
\hline & A'$^{\prime}$-movement & A-movement \\
\hline Case can be assigned to landing site & $X$ & $\checkmark$ \\
\hline Can agree with T in landing site & $X$ & $\checkmark$ \\
\hline Bypasses intervening subjects & $\checkmark$ & $X$ \\
\hline Allows pied-piping & $\checkmark$ & $X$ \\
\hline Landing site can bind anaphors & $X$ & $\checkmark$ \\
\hline Licenses parasitic gaps & $\checkmark$ & $X$ \\
\hline Can induce weak crossover & $\checkmark$ & $X$ \\
\hline Must reconstruct & $\checkmark$ & $X$ \\
\hline
\end{tabular}

Source: Safir (2019, table 1, adapted)

Van Urk (2015) and Safir (2019) take this distinction not to be a primitive of the grammar; rather, they seek to derive the $\mathrm{A} / \mathrm{A}^{\prime}$-distinction from independent principles of the grammar. Both proposals provide a successful account of the properties in Table 1. They differ crucially, however, in what independent components of the grammar they derive the A/A'-distinction from. Van Urk, as well as Obata \& Epstein (2011), argue that the Aor A'-nature of a given syntactic position is determined by the type of feature that creates it. Safir, in turn, proposes that grammar is equipped with an optional operation that adds a layer of structure in a moving nominal. The A- or A'-nature of the movement falls out from whether or not this operation has applied, in combination with independent interface conditions that govern case and agreement.

While it may not be possible to disentagle the two proposals by the properties in Table 1, in this paper, I compare how they fare with respect to a different phenomenon, namely, clitic doubling in Argentinian Spanish.

This paper is organized as follows. In $\S 2$, I outline the two theories of the A/A'-distinction mentioned above. In $\S 3$, I summarize the description and analysis of clitic doubling in 
Argentinian Spanish, as put forth by Di Tullio et al. (2019). In §4, I compare the two theories of the A/A'-distinction based on these data. $\$ 5$ concludes.

\section{Two accounts of the $\mathbf{A} / \mathbf{A}^{\prime}$-distinction}

\subsection{The featural view (Obata \& Epstein 2011, Van Urk 2015)}

According to Van Urk (2015; see also Obata \& Epstein 2011), syntactic positions are defined in terms of the features that create them: A-positions are created by $\varphi$-features, while A'-positions are created by features like Wh, Foc, etc.

(1) Featural view of the A/A'-distinction

All differences between A- and A'-movement derive from the features involved in Agree.

(Van Urk 2015, p. 26)

Under Van Urk's theory, the properties that distinguish A- and A'-movement (cf. Table 1) stem from how the gap of each type of movement is interpreted. (See more details in Van Urk 2015.)

(2) Interpretation rule for A-chains

In a movement structure formed by Agree for $\varphi$-features, adjoin a node $\lambda x$ to the probing head.

(Van Urk 2015, p. 41)

\section{Interpretation rule for $A$ '-chains}

In a movement structure formed by Agree for an A'-feature, adjoin a node $\lambda f$ to the probing head.

(Van Urk 2015, p. 38)

A consequence of this proposal is that a syntactic position assumed to be intrinsically of the A'-type can be an A-position if it is created by $\varphi$-features. However, if Spec-CP can be created by $\varphi$-features, it can also be an A-position. Fong (2019) shows that hyperraising in Mongolian involves a stopover position at Spec-CP and, additionally, that this movement has A-properties. Hyperraising to object is a phenomenon whereby the subject of a finite embedded $\mathrm{CP}$ interacts with the matrix clause regarding case and movement. This is similar to object shift or ECM, except that in hyperraising the embedded subject is crossing a finite domain, which is unexpected under conventional assumptions about the phasehood of a finite CP. In (4a), we see that the subject of an embedded CP (Dulmaa) is marked with nominative case, as expected. In Mongolian, nominative case is morphologically null. However, it can also be marked with accusative case $(-g)$. That this accusative case comes from the matrix clause can be argued on the basis of the fact that it is taken if the matrix verb is passivized (see Fong 2019). Accusative case assignment thus seemingly crosses a finite CP phase boundary.

Fong (2019) argues that the accusative variant of (4a) is derived by moving the embedded subject to Spec-CP, where it is accessible to matrix elements like an accusative case assigner, thereby avoiding a phasehood issue. From there, the embedded subject can hyperraise into the matrix clause (i.e. move or raise, crossing a $\mathrm{CP}$ boundary), as in (4b). In this sentence, the hyperraised accusative subject oyutan büriig 'every student' moves 
from the embedded clause into the matrix clause via the embedded Spec-CP and then binds a pronoun in the matrix clause. The creation of new antecedents for binding is a signature property of A-movement.

(Mongolian, Fong, 2019, 3, 6b)

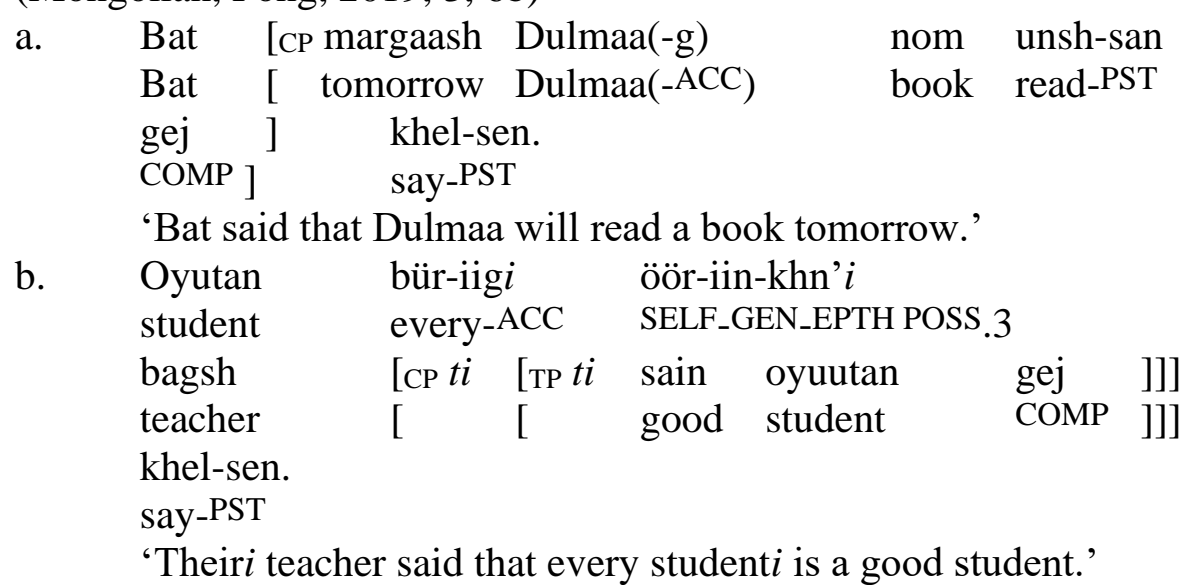

This is unexpected if Spec-CP is intrinsically an A'-position. Conversely, this type of flexibility is afforded by Van Urk's theory.

Likewise, another consequence of this theory is that there could be a syntactic position that displays hybrid, A/A'-behavior, as long as it is created by a hybrid set of A/A'features. Van Urk (2015) contends that Spec-CP can be a hybrid position in Dinka, in that it shows A-behavior for certain properties used to distinguish between A and A'positions, but A'-behavior for the complement set of properties. One of the arguments that the author presents is based on the fact that the phrase that occupies the first position in a sentence triggers $\varphi$-agreement in the verb, which occupies the second position in $\mathrm{C}$. Importantly, the phrase moved to Spec-CP can be a DP that moves across a ccommanding and thus closer DP goal. The hybrid behavior of Spec-CP is revealed by the fact that, while triggering agreement is a property usually associated with A-movement, the ability to skip over a higher potential goal is a property of $\mathrm{A}^{\prime}$-movement.
a. Yî.un $\varnothing$-cí môc tî.ụ.
you 2-PRF.OV man.GEN see. ${ }^{N F}$
'You, the man has seen.'
b. Mìir à-càa tî..̣̂.
giraffe 3SG_PRF.1SG see.NF
'A giraffe, I have seen.'
c. Mičer áa-càa ké tî.ị.
giraffes 3PL_PRF.1SG 3PL see.NF
'Giraffes, I have seen.'
(Van Urk 2015, p. 103)

Data like (5) indicate that Spec-CP in Dinka is a position that displays hybrid A/A'behavior, 1 as expected in a theory where the behavior of syntactic positions is determined by the features that create them.

1 The interested reader is referred to the original source for additional converging evidence. See also Longenbaugh (2017), Colley and Privoznov (2020), and Scott (2021). 


\subsection{The Free merge view (Safir 2019)}

The main ingredient in Safir (2019) is the proposal that a countercyclic Merge operation is freely available which combines a moving DP with a null preposition. The newly formed PP shields the DP away from Agree and case operations. The PP layer also alters the DP's binding capabilities. This operation is dubbed 'Insulation'. If Insulation does not apply, the DP can indeed participate in these operations and its binding capabilities remain unchanged. In Safir's framework, Insulation is a free, costless operation with its effects regulated by interface conditions. In the derivation of a sentence like Who did Mary praise?, Insulation may (6b) or may not (6a) apply to the moving Wh-phrase. If it does, T can Agree with the subject, allowing for the valuation of $\varphi$-features and case. If it does not, the moved $W h$-phrase intervenes between $\mathrm{T}$ and the subject, preventing the aforementioned Agree and case operations. The derivation in (6a) crashes not because A'-movement is postulated to be necessarily Insulated (or A-movement, un-Insulated), but because of independent interface condition that govern case and Agree operations.

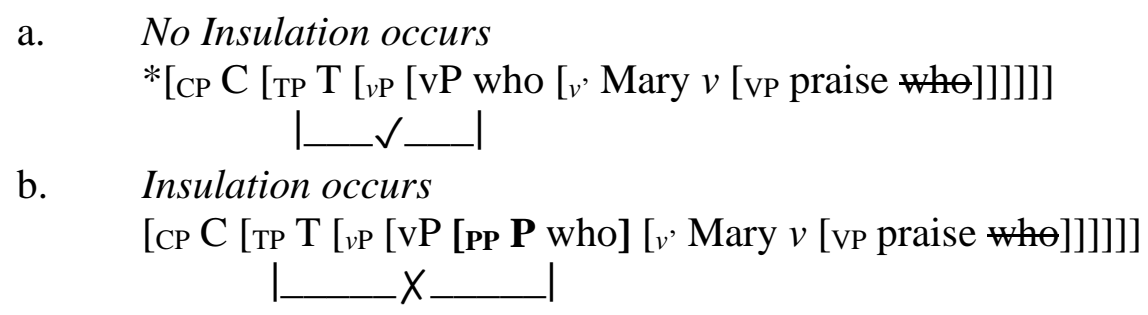

Spec-CP can also flexibly behave as an A-position in Safir's theory: it is possible for Insulation, a free operation, not to apply to a DP moving through this position, as long as Agree and case issues do not arise. The author shows that this indeed the case in passivized wager constructions. The derivation of a sentence like The witch was said to be responsible for the recent influx of mosquitoes can proceed with (7b) or without (7a) Insulation of the witch:

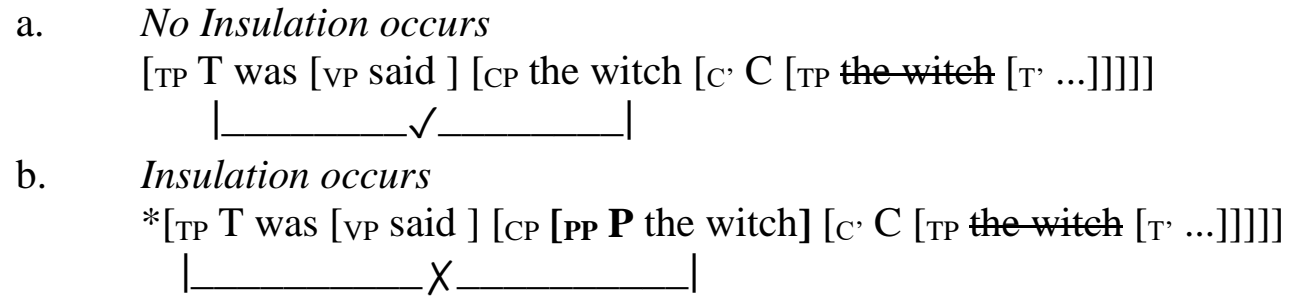

By assumption, the complement of a wager verb is a CP, which prevents ECM of the embedded subject. However, under passivization, this DP would have to escape the CP via its Spec, which is commonly considered to be A'-movement. If the witch is Insulated, the derivation would crash, since this DP would remain caseless throughout the derivation and the matrix T's $\varphi$-features could be not be valued. If Insulation does not apply, these requirements can be satisfied.

In Safir's theory, movement through a phase edge (e.g. Spec- $v \mathrm{P}$ and Speec-CP) is not intrinsically Insulated. Rather, Insulation is free, but its consequences are evaluated by independent restrictions

Having outlined these two theories of the A/A'-distinction, in the next section, we turn to the data that will be resorted to in order to tease these theories apart. 


\section{Clitic Doubling in Argentinian Spanish}

Di Tullio et al. (2019) analyze clitic doubling (CD) of differentially marked objects, which is optional in Argentinian Spanish (8).

$\begin{array}{llll}\text { Santos (la) } & \text { miró } & \text { a } & \text { Rosa. } \\ \text { Santos (CL.3SG.FEM.ACC) } & \text { look.at.PST.3SG } & \text { ACC } & \text { Rosa } \\ \text { 'Santos looked at Rosa.' } & & & \\ \text { (Di Tullio et al., 2019, (2a), adapted) } & & \end{array}$

Furthermore, the authors observe that, in Argentinian Spanish, differential object marking can target non-animate objects, whether they are focus-fronted or not. 2

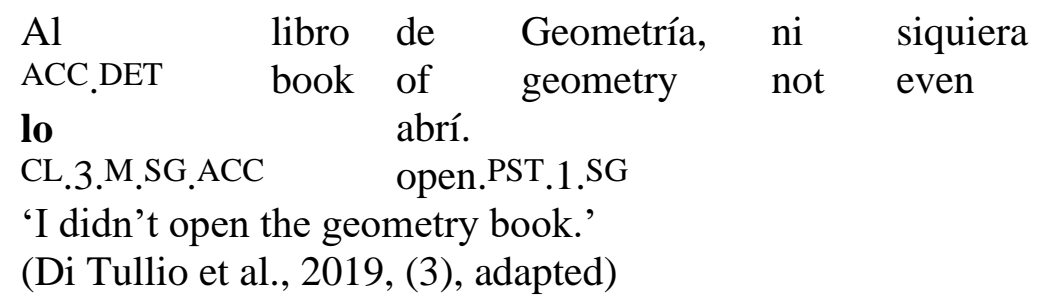

In this paper, we will look at focus-fronted constructions like (9), which Di Tullio et al. compare to focus-fronted constructions without $\mathrm{CD}$. The authors conclude that, when focus fronting is accompanied by $\mathrm{CD}$, it displays properties of A-movement, while focus fronting in the absence of CD displays properties of A'-movement.

Di Tullio et al. remark that focus fronting, accompanied by $C D$, behaves differently from clitic left dislocation (CLLD), even though these constructions may be linearly similar. A difference mentioned by the authors has to do with subject inversion, which is obligatory when a focus-fronted accusative DP is clitic doubled (10), but optional in CLLD (11).3

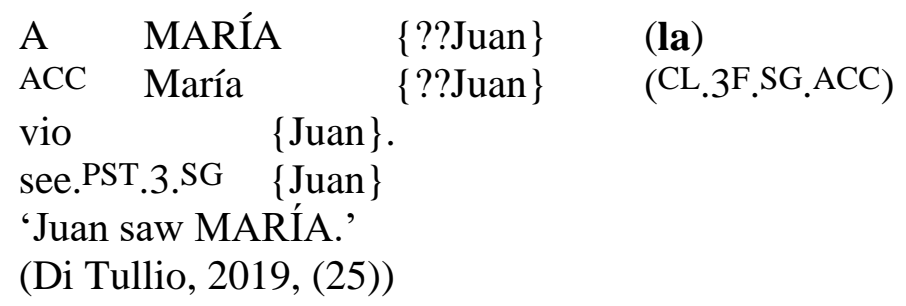

(11) A María, $\{$ Juan $\}$ la ACC María \{Juan\}CL.3.F.SG.ACC see.PST.3.SG $\{$ Juan

'María, Juan saw her.'

(Di Tullio, 2019, (25))

Di Tullio et al. observe that the presence or absence of the clitic is correlated with A- and A'-properties of the clitic doubled DP, respectively. If it is moved across a subject

2 For arguments that (11) has focus properties, see Di Tullio et al. (2019).

3 Di Tullio et al. argue at length that focus fronting CD constructions differ from CLLD. I refer the interested reader to the original paper for further discussion. 
containing a pronoun coindexed with it, no WCO effect is induced (12a). In the absence of $\mathrm{CD}$, a WCO violation arises (12b).

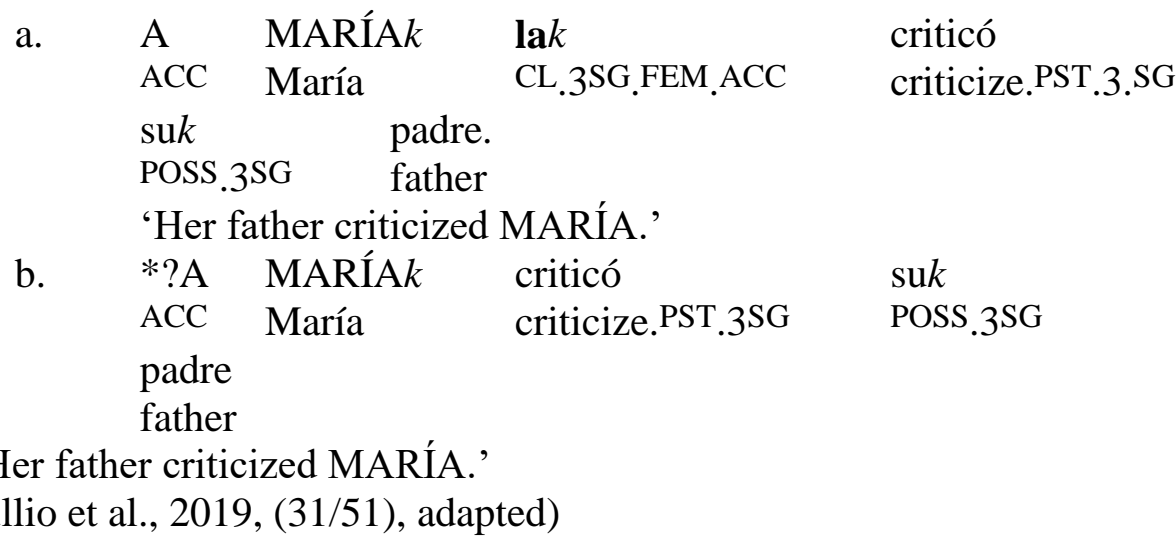

Interestingly, they observe that the position of the bound pronoun is relevant if the fronted CD-ed accusative DP moves from a complement clause. A pronoun in the matrix clause cannot be bound by the fronted DP (13), while a pronoun that is also in the embedded clause can (14).

\begin{tabular}{|c|c|c|c|c|}
\hline$?^{*} \mathrm{~A}$ & JUAN $i$ & $i$ cree & $\underline{\mathrm{su} i}$ & profesor \\
\hline $\mathrm{ACC}$ & Juan & believe.PRS.3.SG & POSS.3.SG & professor \\
\hline que & lo $i$ & & criticó & María \\
\hline hat & CL.3.M & 1.SG.ACC & criticize.PST.3.SG & María \\
\hline $\begin{array}{l}10 \\
10 t\end{array}$ & $\begin{array}{l}\mathrm{a} \\
\mathrm{ACC}\end{array}$ & $\begin{array}{l}\text { Pedro). } \\
\text { Pedro) }\end{array}$ & & \\
\hline
\end{tabular}

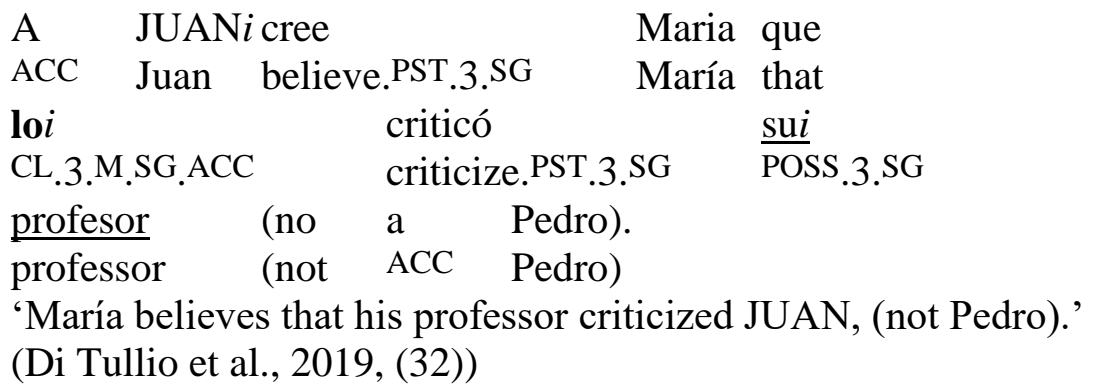

Furthermore, a clitic doubled DP does not reconstruct (15a). Without $\mathrm{CD}$, reconstruction is possible (15b).

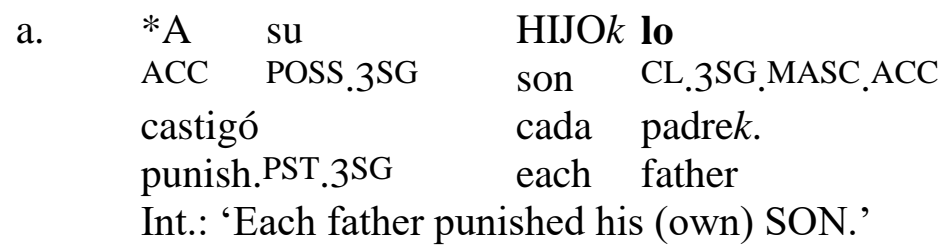




$\begin{array}{lll}\text { b. } & \text { A } \quad \text { Su } & \text { cada. } \\ \text { ACC POSS.3SG } \text { son punish. PST.3SG } & \text { each } \\ \text { padrek. } & \\ \text { father } & \\ \text { 'Each father punished his (own) SON.' } & \\ \text { (Di Tullio et al., 2019, (58), adapted) } & \end{array}$

Finally, Saab (2021) shows that there is difference, albeit a subtle one, between focusfronting with $\mathrm{CD}$ and without it regarding reconstruction for Condition $\mathrm{C}$ : the former (16a) avoids a Condition $\mathrm{C}$ violation more easily than the latter (16b).

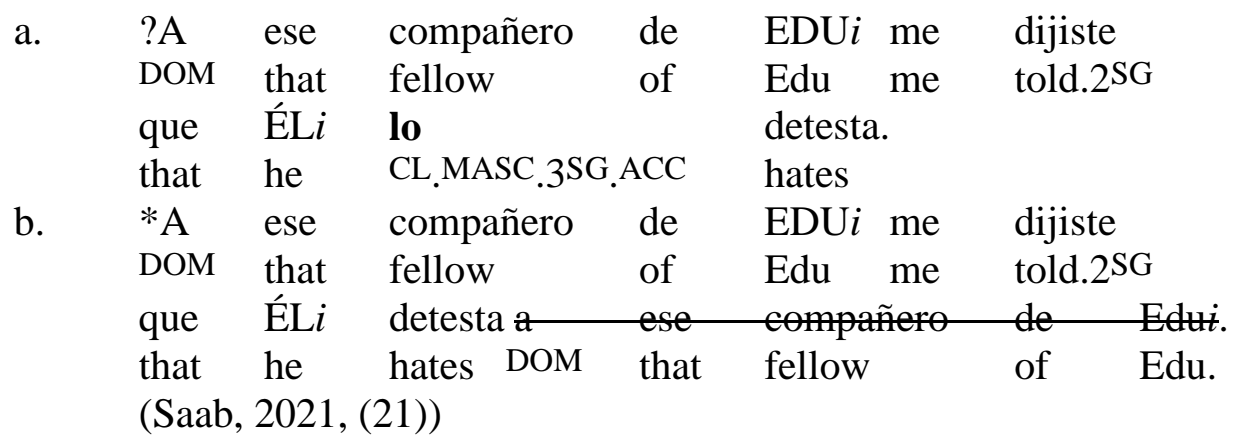

In sum, the A- and A'-properties of focus fronting with and without $\mathrm{CD}$ are summarized below:

Table 2. The A/A'-differences between focus-fronting with and without CD

\begin{tabular}{|c|c|c|}
\hline & $\begin{array}{c}\text { Focus fronting } \\
\text { with CD }\end{array}$ & $\begin{array}{c}\text { Focus fronting } \\
\text { without CD }\end{array}$ \\
\hline Obviates a WCO violation & $\checkmark$ & $X$ \\
\hline Reconstruction & $X$ & $\checkmark$ \\
\hline Reconstruction for Condition C & $?$ & $X$ \\
\hline
\end{tabular}

Two anonymous reviewers ask about the remaining properties of the A vs. A'-distinction, as summarized in Table 1. The description provided by Di Tullio et al. lead to the expectation that focus fronting with clitic doubling and focus fronting without should behave as A-movement and A'-movement, respectively, with respect to these other properties. These properties are not explicitly discussed by the authors, but we can go over a few of them here. Case assignment distinguish between A- and A'-movement. This property does not apply here, since the object that undergoes focus fronting can be assigned accusative case in situ, prior to any movement. Because of that, it cannot Agree with $\mathrm{T}$ either. The object just mentioned does not move across a subject, as will be made clear below wehn we discuss the derivation outlined in (19). Pied piping is another property that is not applicable here, since the clitic double DP that undergoes focus fronting is also Differentially Marked. DOM in Spanish targets direct objects. The data employed to discuss WCO (i.e. (12)-(14)) can also be used to illustrated binding, so the creation of new antecedents for binding is also covered in the data described above. The only remaining property left undiscussed is the licensing of parasitic gaps. I leave these data for future work, but contend that the data that Di Tullio et al. do examine make for a 
convincing case that focus fronting can involve a step of A-movement, depending on whether or not it is also accompanied by clitic doubling.

Di Tullio et al. assume that Spec- $v$ P can count as either as A- or A'-position, depending on the features that trigger its creation. They propose that CD is triggered by a [PERSON] feature in the object and, furthermore, that this feature is optional in Argentinian Spanish.

\section{The Person Feature Condition on $C D$}

$\mathrm{CD}$ is triggered by person features on pronominal/DP objects.

(Di Tullio, 2019, (41))

Lexical DPs in Argentinean Spanish are optionally assigned with a [3Person] feature in the syntax.

(Di Tullio, 2019, (46))

According to the authors' proposal, the doubling pronoun is the PF effect of the [PERSON] agreement that takes place at Spec- $\nu \mathrm{P}$.

Alternatively, one could extend Kramer's (2014) analysis of CD in Amharic, which also displays properties of A-movement. According to Kramer, $\mathrm{CD}$ in this language is the product of $\varphi$-features in $v$, which trigger the movement of a DP to Spec- $v$ P. The clitic is the exponent of M-Merger between the head D of the moved DP and $v$. Yet another analysis that could be extended to Argentinian Spanish is Harizanov's (2014) theory of $\mathrm{CD}$ in Bulgarian, which also displays properties of A-movement. Harizanov also proposes that $v$ may have $\varphi$-features, which trigger the movement of a DP to Spec- $v$ P. The doubling clitic is a partial copy of this movement chain.

The common thread unifying these analyses is A-movement to Spec- $v \mathrm{P}$ (19a). In the absence of a [PERSON] feature in the object (in Di Tullio's original analysis) or in the absence of $\varphi$-features in $v$ (if one adopts Kramer's or Harizanov's analyses), the object has to A'-move through Spec-vP (19b).

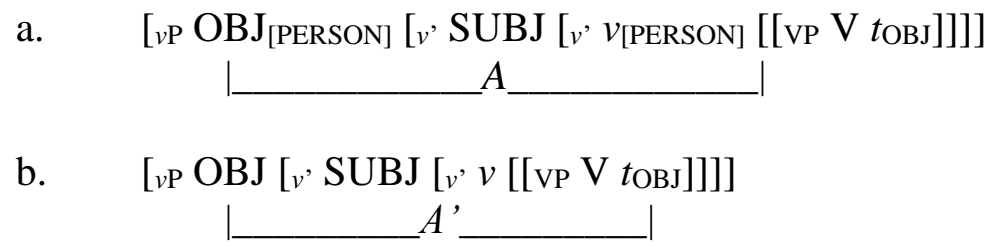

In sum, (19a) represents the initial step of CD of the accusative DP (i.e. A-movement to a higher Spec- $v$ P above the subject), while (19b) represents an intermediate step of focus fronting without CD. After this initial step of A- or A'-movement, the DP is finally focusfronted, a type of $\mathrm{A}^{\prime}$-movement, according to conventional assumptions. More specifically, one could assume in (19b) that edge features are inserted at phase heads to drive intermediate movement that does not check or value any feature. By assumption, edge features are of the A'-type (Chomsky 1995). Conversely, the movement of the object in (19a) is triggered by a particular feature (specifically, a $\varphi$-feature), so, under the assumptions made by Di Tullio et al. and those made in this paper, this is an instance of A-movement. 4 
Two anonymous reviewers ask whether A-movement of an object across a subject incurs a violation of locality, since A-movement should target the highest DP, while A'-moving an object across a subject does not violate any minimality rule. The A-movement involved in the data examined here does not incur such violation because it includes an intermediate step through Spec-vP, as depicted in (19a). Importantly, this movement is triggered by a feature in v. Only the object is in the c-command domain of this feature, which excludes the subject. As such, no locality principle is violated because, at this point of the derivation, the subject is not a candidate to move. Subsequently, because on (19a), the object ends up in a higher position than the subject, it can further A'-move without incurring a locality violation at this step of the derivation as well.

Given the properties of A-movement, the absence of WCO effects and of reconstruction displayed by clitic doubled DPs can thus be modeled as consequences of the fact that this nominal is undergoing A-movement. Di Tullio et al. assume further that [PERSON] may be optional in 3rd person DPs in Argentinian Spanish. That [PERSON]-less DP must then $\mathrm{A}^{\prime}$-move to Spec- $v \mathrm{P}$. Consequently, this DP is expected to induce WCO effects and be able to reconstruct. This analysis is also able to account for why only a pronoun in an embedded clause (and not located in the matrix clause) can be bound by a CD-ed fronted accusative DP. According to the analysis, only the first step of movement (the movement to Spec- $\nu \mathrm{P}$ ) is an instance of A-movement. Only at this point of the derivation can the CD-ed object bind a pronoun. If the pronoun is located higher up in the structure (e.g. if it is located inside the matrix subject), it cannot be bound by the moving CD-ed object because movement at this point is of the A'-type.

Having summarized Di Tullio's description and analysis of CD in Argentinian Spanish, in the next section, we employ these data to evaluate the theories of the $\mathrm{A} / \mathrm{A}^{\prime}$-distinction discussed in $\S 2$.

\section{Comparing two theories of the $\mathbf{A} / \mathbf{A}^{\prime}$-distinction}

Di Tullio et al.'s analysis can be cast as a representative of Van Urk's featural view of syntactic positions (specially if one adopts Kramer's 2014 or Harizanov's 2014 implementations), since Spec- $v \mathrm{P}$ is considered to be an A-position created by the valuation of a $\varphi$-feature.

Safir's Free Merge theory is also flexible in not assuming that syntactic positions are inherently A or A'. Could it also account for Argentinian Spanish CD? If Insulation applies to the moving clitic doubled DP (20b), T can successfully Agree with the subject across it. However, because the clitic doubled DP is Insulated, it is expected to exhibit A'-properties, contrary to fact. If Insulation does not apply (20a), the clitic doubled DP is expected to display A-properties, as desired. However, this derivation crashes because T cannot Agree with the subject.

(20) a. No Insulation occurs

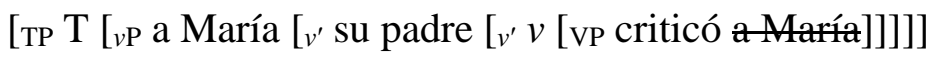

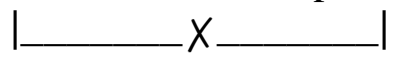

b. Insulation occurs

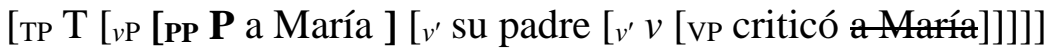

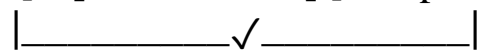


Safir's Free Merge theory provides two possible derivations of the Argentinian Spanish clitic doubling data in $\S 3$. Both of them, however, yield undesirable results.5

\section{Concluding remarks}

Both Van Urk (2015) and Safir (2019) strive to characterize the A/A'-distinction as a descriptive device. In other words, for these two theories, the A/A'-distinction is not a primitive of grammar, being the byproduct of more general principles of the grammar instead. These theories differ in how this distinction is derived, but they are both successful in accounting for the phenomena usually employed to characterize the A/A'distinction (cf. Table 1). They are also successful in allowing for a flexible definition of syntactic position. In this paper, I argued that CD in Argentinian Spanish, as analyzed by Di Tullio et al. (2019) help us to distinguish between these theories.

\section{References}

Chomsky, Noam. 1995. The minimalist program. MIT Press, Cambridge, MA.

Colley, Justin, and Privoznov, Dmitry. 2020. "On the topic of subjects: composite probes in Khanty". Proceedings of the 50th annual meeting of the North East Linguistic Society (NELS). UMass Amherst: GLSA Publications.

Fong, Suzana. 2019. "Proper movement through Spec-CP: An argument from hyperraising in Mongolian". Glossa: a journal of general linguistics, 4(1). http://doi.org/10.5334/gjgl.667

Harizanov, Boris. 2014. "Clitic doubling at the syntax-morphophonology interface". Natural Language \& Linguistic Theory, 32(4), pp.1033-1088. https://doi.org/10.1007/s11049-014-9249-5

Kramer, Ruth. 2014. "Clitic doubling or object agreement: The view from Amharic". Natural Language \& Linguistic Theory, 32(2), pp.593-634. https://doi.org/10.1007/s11049-014-9233-0

Longenbaugh, Nicholas. 2017. "Composite A/A'-movement: Evidence from English tough-movement”. Ms., MIT. https://ling.auf.net/lingbuzz/003604

5 A reviewer asks whether the dative preposition that appears in the clitic doubled DP would count as a reflex of Insulation. A full analysis of Differential Object Marking is beyond the scope of this paper, but it is not necessarily clear that what surfaces as the DOM strategy employed in Spanish is a preposition, at least not in the sense of the null P that is crucial to Safir's Insulation. It could be the case that $a$ is some case morphology realization that happens to be prenominal instead of suffixal. Something else that exceeds the goals of this paper is how the regular (i.e. non-differential) mechanisms of case assignment of a given language interact with DOM. Insulation affects the former (assuming that both Insulation and case assignment are narrow syntactic operations), but not necessarily the latter. 
Obata, Miki, and Samuel David Epstein. 2011. Feature-Splitting Internal Merge: Improper Movement, Intervention, and the A/A' Distinction. Syntax, 14(2), pp.122147. https://doi.org/10.1111/j.1467-9612.2010.00149.x

Saab, Andrés. 2021. From free pronouns to probes: A theory for a subset of Spanish clitics. Lectures notes for the Anglia Ruskin-Cambridge Romance Linguistics Seminars.

Safir, Ken. 2019. “The A/Ā distinction as an epiphenomenon". Linguistic Inquiry, 50(2), pp.285-336. https://doi.org/10.1162/ling_a_00305

Scott, Tessa. 2021. "Formalizing two types of mixed A/Ā movement". Ms., UC Berkeley. https://ling.auf.net/lingbuzz/005874

Di Tullio, Ángela, Andrés Saab, and Pablo Zdrojewski. 2019. "Clitic Doubling in a Doubling World: The Case of Argentinean Spanish Reconsidered." In The Syntactic Variation of Spanish Dialects, pp. 215-244. Oxford University Press https://dx.doi.org/10.1093/oso/9780190634797.001.0001

van Urk, Coppe. 2015. A uniform syntax for phrasal movement: A case study of Dinka Bor. PhD dissertation, Massachusetts Institute of Technology. 